\title{
Integrated Learning of Autistics in Primary School through Computer
}

\author{
Sumalee Chanchalor ${ }^{1}$, Krislada Chusinkunawut ${ }^{2}$. \\ ${ }^{1}$ Faculty of Industrial Education, King Mongkut's University of Technology Thonburi, \\ Bangkok Thailand. \\ ${ }^{2}$ The Institute for the Promotion of Teaching Science and Technology, Sukhumwit, \\ Bangkok Thailand.
}

\begin{abstract}
Various types of computer multimedia are used for education. It is questioned if autism could relieve or learn anything through this media. The sample group consisted of five autistic students, in the school, aged between 11 - 15 years old. Integrate art activities, game and folklore on computer multimedia were designed to be a tool for autistic learning. They were observed and tested to find out the result.

After six weeks learning by integrated activities; art, game and folklore through computer multimedia, They all improved their abilities to learn about colors. Four in five autistics students' behaviors was improved in every aspect.
\end{abstract}

Keywords: Learning through computer / autistic students/art activities/folklore/ game.

\section{Introduction}

Autism is a mental problem which originates from a brain disorder. It affects persons' ability to communicate [1] and repetitive behaviors. Children with autism may fail to respond to their name and often avoid eye contact with others[2.] Main problems are behavioral and emotional ones. Autistic children lack self-discipline. They look for and mess things up and then do not keep them in the right place. They walk around while a teacher is teaching. They are impetuous, short-concentrated, absent-minded, and irresponsible. They shirk their work which attempts are required. They usually have self-abusive behavior, such as biting or head-banging. Some speak in a singing voice about a narrow range of favorite topics, with little regard for the interests of the listeners [2.] Autism prefers to play alone and does not make eye contact with other people. The categories of symptoms might be social interactions, verbal and nonverbal communication and limited interests in activities or play [3.] Autism cannot be completely cured, its treatment is to stimulate development, to modify behavior, to employ music therapy, speech therapy and art therapy, in order to reduce undesirable behavior and create appropriate behavior instead[4.]

Art has an important role in nurturing children's physical, emotional, social and intellectual development. Nicole Martin [5]mention that art making is beneficial to people, particularly with autism, due to their intense sensory needs and non regulation, often nonverbal nature, and need for more visual, concrete, hands-on therapies. The characteristics of the disorder, may be reduced by $2 / 3$ with early diagnosis and appropriate interventions such as art therapy[6.] Nowadays, computers have a role in many aspects. Using computers to stimulate autistic children's development may be one of useful methods, but it has never been stu- 
died in special case. Perhaps people use technology in order to treat ailments, illness and disability in several ways, especially in medical field.Most computer applications designed for people with autism focus on the relationship between computer and users, and aim to help with specific behavioral problems associated with autism.

It is questioned if integrating art, game and folklore activities on computer can encourage and improve autistic children's behavior or not. This research focused on studying autistic children's ability to distinguish colors, to encourage them to have social desirable behavior. This study will acquires information for setting the development of learning media for autistic children. It will also acquire qualitative and practical lessons on multimedia as a supplement to autistic children's learning in special classroom.

\section{Objectives}

2.1 To study the ability to distinguish and name colors of autistic children who participated integrated activities.

2.2 To study the behavior of autistic children who have participated this integrated activities.

\section{The Scope of the Research}

Contents: Art study; colors, lines, shapes and forms, ocial studies; Self-discipline: to keep personal and other people's stuff, to support and to share among one another and to abide by the rules politely.

\section{Methodology}

Sample: Five autistic students, aged between 11-15 years, who studied at primary level, special classroom. They were learning ability.

Data Collection: This research is experimental and qualitative research. Inte- grated activities on computer were constructed including similar tones of color in a nearby distance. The children had to paint in the frame and tell colors names. Autistic students were asked to do these activities on computer for six weeks, each week three times. A test on colors distinguishing was also developed. Autistic children's behaviors were observed while conducting learning activities. The data of their abilities were recorded before and after the experiment. Their ability on colors was calculated in percentage.

\section{Results}

After learning with compute by setting integration activities, it was found that four in five autistics abilities to name, to paint and to distinguish color were improved clearly. Table 1. showed their ability before and after participating activities through computer multimedia which each one can learn and improve.

Table 1. Percent of autistics students' ability before and after participating the activities.

\begin{tabular}{ccccccc}
\hline \multicolumn{3}{c}{$\begin{array}{c}\text { Name color } \\
(\%)\end{array}$} & \multicolumn{3}{c}{$\begin{array}{c}\text { Paint color } \\
(\%)\end{array}$} & \multicolumn{2}{c}{$\begin{array}{c}\text { Distinguish color } \\
(\%)\end{array}$} \\
\hline Child no. & Before & After & Before & After & Before & After \\
1 & 75.00 & 100.00 & 75.00 & 100.00 & 66.67 & 100.00 \\
2 & 75.00 & 100.00 & 75.00 & 100.00 & 66.67 & 100.00 \\
3 & 66.67 & 100.00 & 66.67 & 100.00 & 33.33 & 100.00 \\
4 & 66.67 & 100.00 & 66.67 & 100.00 & 33.33 & 100.00 \\
5 & 50.00 & 91.67 & 50.00 & 91.60 & 00.00 & 66.67 \\
\hline
\end{tabular}

After learning through electronic module, all of autistics' abilities on color were improved. By observation the children and the teacher's record, the children's behaviors were improved in many aspects as the following:

The $1^{\text {st }}$ Person: This child had illdisciplined and aggressive behavior. $\mathrm{He}$ untidily kept his personal stuff. When no one responded to his needs, the child would harm himself. He could neither bear listening to any sounds or words, nor speak appropriately. After learning the 
module through computer multimedia, this child could keep his belonging in the right place but not in order. He shouted for help when he couldn't find it. He was unwilling to share others. At first, he separated his table away in order that his friend couldn't use shared objects. Then, he allowed his friends to use the shared objects without making terrible noise. $\mathrm{He}$ could follow classroom regulation such as not shouting or throwing things when he had to follow the regulation which he didn't like. He could accept the teacher's comment calmly and being in his place.

The $2^{\text {nd }}$ Person: The child would untidily keep his personal stuff therefore he could not find his stuff and often lost it. He was always generous to help a classroom's assignments. He could draw pictures to communicate with other people in order that they understood what he wanted to express and could paint pictures by crossing the lines. After the experiment, this child could keep his belonging in the right place before doing other activities. He helped his friends and shared things more than before, however he still stared at his friends who used the share objects. He could follow the regulation such as to stop doing his interested activities in order to join with learning in class. He could accept the teacher's comment without making terrible noise, but only stared at his teacher.

The $3^{\text {rd }}$ Person: The child was not talkative. Sometimes, he would say something to himself. He untidily kept his personal stuff therefore his was often lost. He could draw pictures to communicate with other people. His assignments were moderately clean and neat. They were correct at $60 \%$. After the experiment, this child could keep his belonging in the right place and in order before doing other activities. He shared but stared at his co-users until they returned things back. Finally, he could share and follow the regulation. When the teacher told him to stop doing his interested activities, he kept quiet, made unemotional noise. $\mathrm{He}$ accepted the punishment when violated regulations even though he stared the teacher and scratch his nail.

The $4^{\text {th }}$ Person: The child had illdisciplined and aggressive behavior. $\mathrm{He}$ walked and came while working. $\mathrm{He}$ untidily kept his personal stuff. He could draw pictures to communicate with other people in order that they understood what he wanted to express. He could paint pictures by crossing the lines. He was easily distracted by external stimuli. $\mathrm{He}$ was absent-minded at intervals while working. His assignments were clean and neat moderately. They were $50 \%$ correct. After the experiment, this child could keep his belonging in the right place but not in order. He kept things in the case which was still on the desk. He lent things to his friends but unwilling to give the shared objects. He behaved politely according to the rules but hikes his eyes from the teacher and do other activities.

The $5^{\text {th }}$ Person: The child had illdisciplined behavior. He walked around while learning and during other children was working. He picked and messed things up and did not keep them in the right place. Then, it was necessary for him to have a teacher or a care taker to give him a hand. He was not good at painting pictures within the lines which were dirty and ill-organized. He lacked of responsibility and interest in assignments. He was easily distracted by external stimuli, absent-minded at intervals while working. His work was correct less than $50 \%$. After the experiment, he developed the least. He could neither put things in the right place nor in order. He shared more than before but still stared at users. $\mathrm{He}$ stared at the teacher with a bit murmur when the teachers told him to behave according to the regulation. 


\section{Conclusion and Discussion}

Learning condition of this study is in the environment of school. There was the evident to support that autistics children could learn and improve their mental abilities such as name colors correctly, paint and classify the different colors better than before. By doing the activities in the computer media which present in form of art activities, they could repeat it again and again. When they success doing their jobs, they received the rewards. Thus they were happy to do this job because we provided it in form of games. Richard,G.L.[4] mentioned that music therapy, speech therapy and art therapy is able to be the treatment to stimulate autism development and to reduce undesirable behavior and to create appropriate behavior instead. Betts [6] mentioned that appropriate intervention such as art therapy may reduce the characteristics of the disorder.

We've seen that some symptoms of were improved as desirable behavior in society. They could accept the regulation better. The sample might learn and adapt their behavior from the tales in computer multimedia which we presented contents, pictures and voice. The content we present in folklore are "the actor who behave well, receive good results, the actor who has poor behavior, receive bad results." They might absorb and imitate the actions of actors in the story. Thus the children could learn some good behaviors from the lesson on computer multimedia. This study supported the beneficent of learning experience of autism through computer multimedia. However, we should concern to the appropriate content which present to them. The learning activities integrate art and folklore supported their abilities on color and concentration. They had to concerned to what they did in order to do the provided activities. Game is the strategy which arouses them for attentive learning. Moreover, the content of folklore supports their suitable social behavior. The study of Chiyadeach[7] found that Thai students who had experiences in folk game had higher basic mathematics skills than those who had experiences in ordinary games. Thus we might claim that this technology are able to motivate children with autism. They are often highly interested, motivated and thus attentive to video [8.]

\section{References}

[1] Schoenstadt Authur.2011a. "Autism." http://autism.emedtv.com/autism/ au .html.

[2] Schoenstadt A. 2011b. "Autism symptoms." http://autism.emedtv. $\mathrm{com} /$ autism/autism-symptoms.html

[3] Roxanne Dryden-Edwards, MD. "Autism treatment." www. Emedicinehealth. com/autism/ page7_em.htm.

[4] Richard,G.L. (2000. ) "The Source for Treatment Methodologies in Autism." East Molin: Lingui System,p.5-9.

[5] Nicole Martin (2011.) "Art therapy and Autism : explanation." http:// art therapy and autism.com.

[6] Donna Betts. "Art therapy and Autism" http://www.art.therapy.us/.htm.

[7] Chiyadeach N., Nilvichin H. and Churngchow C. (2005.) "Effects Folk Game Experiences on Basic Mathematics skills of Young Children Using Thai as a Second Language in Changwat Pattani, , Journal of Education. Prince of Songkla University,V.16,1(2005.)

[8] Hileman, Camilla K.1996. "Computer Technology with Autistic Children," Autism Society of America National Conference, Milwaukee, Wisconsin, July 19, 1996. 